\title{
Research on the Construction of Characteristic Specialty in Application Oriented Universities
}

\author{
Tao Li \\ Baicheng Normal University, Baicheng, Jilin, 137000, China \\ email: 2975777902@qq.com
}

Keywords: Application oriented undergraduate colleges; Specialty construction; Research

\begin{abstract}
This paper analyzes the connotation of applied undergraduate colleges and professional characteristics, discusses some problems existing in the process of construction specialty at present. To solve these problems, we combined with the research, put forward some corresponding countermeasures and suggestions, and hope to improve the characteristics of applied undergraduate specialty construction and construction level the quality of help, promote the pace of the construction of characteristic specialty of applied undergraduate colleges.
\end{abstract}

\section{Introduction}

The strength and school characteristics of applied undergraduate colleges can show through its specialty, strengthen the construction of professional characteristics, which can improve the school's influence and visibility, but also play a huge role in the limited teaching resources, greatly enhance the application-oriented universities competitiveness. At present, application-oriented universities in the construction of characteristic specialty also exist many problems, such as basic characteristic specialized construction is not solid, lack of monitoring and evaluation mechanism, lack of vitality in the process of the characteristics construction.

\section{The Definition of Application Oriented Undergraduate Colleges and the Characteristic Specialty}

The teaching aim of application oriented undergraduate colleges is to carry out the applied education for the students, and then to cultivate the applied talents to meet the needs of social development. Talents in applied undergraduate colleges are cultivated with solid basic knowledge, strong practical ability and good comprehensive quality and other characteristics. They can be the front line to act as organizers and managers, and can go to the occupation colleges become an excellent teacher. In the cultivation of talents, it needs to enable students to quickly adapt to development and regional society. We will focus on training to enhance students' application ability, curriculum design and teaching methods must be as the center to cultivate students' application ability.

Characteristic specialty refers to undergraduate colleges and universities in accordance with the guidance of the concept of a specific school, they constantly enhance the corresponding professional construction and teaching reform, after a long period of practice. In fact, firstly, the characteristics of the professional have excellent, efficient teaching staff. Secondly, the basic teaching facilities are perfect. And there are schools to provide adequate funding to support teaching activities, the teaching results are very significant, trained people to conform to the new era of social demand, the specialty has more broad prospects, more vitality.

\section{Some Problems in the Construction of Characteristic Specialty in Application Oriented Universities}

The Vitality of Characteristics Professional is not Strong Enough. The characteristics of application-oriented universities professional construction is based on the actual market demand for talent, adjust to the professional construction, cultivate applied talents can make a contribution to 
the market economy. Therefore, the construction of characteristic specialty has obvious industry characteristics, but in the actual construction specialty in many applied undergraduate after the completion of the construction of characteristic school professional, not perfect management of its development, there will be closely linked with the teaching activities and the market demand, when the industry appears some changes did not timely adjustment of the special industry, which leads to the specialty of the students cannot keep up with the pace of market development, cannot make contribution to the development of the market economy, resulting in specialty lose their advantage in the market competition and the development of the fierce, gradually lose vitality.

Inadequate Infrastructure. The construction of characteristic specialty requires not only large teachers and the management team also cannot do without assistance, the basic hardware facilities such as libraries, practice base and laboratory. At present many school of Applied Undergraduate Colleges in short time, the lack of adequate teachers to improve the teaching activities, no reasonable structure of curriculum design, the lack of some high level and the high level academic backbone and academic leaders, in terms of hardware facilities, equipment is not complete, the existing facilities can not be combined with the teaching content of the specialty, resulting in a lot of practice course is very difficult to carry out, not the effective training of students practical ability, and cannot be the characteristics of a professional teaching advantage to play out.

Lack of Perfect Monitoring and Evaluation Mechanism. The establishment of monitoring and evaluation mechanism can effectively promote the specialty construction process, provides basic standards for the construction of characteristic specialty. Applied undergraduate colleges to better the construction of specialty, cannot do without the monitoring and evaluation mechanism. But the actual running process in application-oriented institutes, specifically for monitoring with the characteristics of a professional evaluation mechanism is extremely lacking, there is no scientific evaluation index is reasonable. Due to the lack of monitoring and evaluation mechanism to improve the construction of application-oriented universities without direction in the process of building the characteristics of professional, not really limited resources in the specialty of applied and play, thus greatly increase the difficulty of the construction of Characteristic Specialty.

\section{Measures to Strengthen the Characteristic Specialty Construction in Applied Undergraduate Colleges}

Do a Good Job in Market Research and Investigation. Construction of the characteristic specialty in accordance with social development, first of all need to do a good job in market research and investigation and understand the market demand for talent, and then analyzes the advantages and disadvantages in the process of the characteristic specialty construction, and avoids the influence of the adverse conditions for the characteristic specialty construction.

External investigation. Before the characteristics specialty construction in applied undergraduate colleges, our country and some local policies can be referred to, which are a very important external environment in characteristic specialty construction and need to be focused on research and analysis. When constructing the applied undergraduate colleges, national policies must understudied in detail, planning guidelines of the state and local government education departments for characteristic specialty construction of college, and the demand for applied talents in the development of regional economy, so that in specialty construction we can better grasp the direction of residential construction and build regulations corresponding planning work ahead of time. At the same time, we also need to have a certain understanding of the characteristic specialty construction of the same type of school and do research work well, to prevent problems of other schools in the characteristic specialty construction and avoid market saturation and losing competitiveness because of similar professional excessive. Only doing these external research work well, in the construction of characteristic specialty, the applied undergraduate colleges can better grasp the key point of the characteristic specialty construction, and build a more distinctive and competitive professional.

Internal analysis. In the process of specialty construction, it is necessary to do a good job of internal analysis, which is also one of the main links of professional construction. The construction of characteristic specialty can be combined with the actual development of the school, which just 
ensure the construction of characteristic specialty is more in line with the specific development needs of the school. In the internal analysis, current situation of teaching resources first is needed to have a comprehensive grasp and understanding, and then analyze the ability of a characteristics professional construction according to the existing resources, find advantages and disadvantages of the characteristic specialty construction, and foster strengths and circumvent weaknesses to build development orientation of specialty.

Do a Good Job in Infrastructure. Strengthen the construction of teaching staff. Excellent teachers are the premise of specialty construction of application-oriented universities in the specialty construction; we must do a good job in the construction of teachers' team, improve the relevant system and incentive mechanism in the construction of teachers' team, and then ensure the quality of the construction of teachers' team. In the construction of teaching staff, first it is necessary to introduce and cultivate teacher talents, associated with the characteristic specialty construction, especially some high level leaders, technical backbone, build a scientific and reasonable teacher echelon, and ensure the teaching team of research and teaching quality; Secondly, we can increase the benefits of the professional teachers and attract excellent teachers; Finally, it is necessary to improve the reward system, and appropriately allocate a number of priority places for promotion of the title, and actively encourage the teachers characteristics professional to practice further education and improve the teaching level.

Perfect teaching facilities. Perfect teaching facilities can provide a good foundation for the development of specialty, such as teaching practice base, teaching materials, books and other teaching equipment. In the aspect of teaching practice base, it is necessary to strengthen the teaching practice base construction efforts, increase the teaching resources for the practice of specialty development, and set up a practice system in accordance with the features of professional development, increasing practice course to make the practice occupy a greater proportion in the whole teaching process, to intensify the implementation of students' creative work, thus the students of characteristics professional with strong innovation ability and practice ability. In the preparation of teaching materials, we can learn from the excellent teaching materials related at home and abroad, according to the actual situation of the school for the corresponding adaptation, through the reform of teaching contents and teaching methods, highlighting the professional features prominent. In books and other teaching equipment, it may be appropriate to increase the construction funds to buy some books in print or electronic documents to improve document quality and integrity, and provide advanced Internet multimedia resources to students to let students grasp the latest market demand and better improve themselves.

Do a Good Job of Teaching Management Reform. The reform of teaching management can enhance the teaching quality of the applied undergraduate colleges and promote the development of specialty. Doing a good job in teaching management reform, first of all, can increase the academic atmosphere of the undergraduate colleges and universities, to lay a good environment for the cultivation of professional talents; Secondly, through the reform of teaching management, to provide more autonomy for the specialty of the college or department, the relevant departments can be adjusted according to the actual situation of professional development; Finally, through the reform of teaching management, we can better play the students' personality and improve their learning efficiency.

Construct practice base. In the practice base construction, it is necessary to consider the construction of the campus practice base and the construction of the off campus practice base, so as to support and promote each other. In the construction of the campus practice base, the construction will be focused on the innovation of the management system and the reform of the operation mechanism, which makes the construction of the practical base more practical. In the construction of practice base outside the school, for subject to resource constraints, the school alone cannot build the ideal practice base, who can cooperate with enterprises and other institutions to joint development and construction practice base, laying a good foundation for the development of a specialty. 


\section{Improve the Monitoring and Evaluation Mechanism}

Improving the monitoring and rating mechanism belongs to the specialty, can build the development situation of the specialty of objective evaluation, can make objective evaluation for characteristics specialty in the construction and development, which can help the specialty to find the problems in time and correct them of the timely.

Construct teaching quality guarantee system. The construction of the teaching quality guarantee system can provide the necessary guarantee for the improvement of the teaching quality and the construction of Characteristic Specialty. At the same time in the construction of teaching quality assurance system of the applied undergraduate colleges, not only to the specific teaching objectives, characteristics and functions of the organization, the daily teaching information feedback, quality assessment and other factors as a reference, but also to ensure the implementation of the teaching quality guarantee system, can be applied in the process of teaching management and execution. The teaching quality guarantee system are the common characteristics of curriculum assessment, professional assessment.

To quantify the evaluation and assessment standards of specialty. Relative to other majors, professional specialty is more outstanding and unique, so in the evaluation, cannot perform the same with other ordinary professional standards, to the actual situation of general standard and characteristic evaluation professional combination, establish new evaluation standards more in line with the professional characteristics, and improve the quality of the characteristics of a professional evaluation, carry out evaluation on the characteristics of professional use of specific quantitative evaluation index, so as to ensure the healthy development of professional characteristics.

Monitoring and evaluation mechanism. The specific features of the professional teaching quality can not only rely on the students' test scores to decide, also need to consider the employment situation of students. In the establishment of monitoring and evaluation mechanism, the internal and external evaluation mechanism combination, not only let the school related departments involved in monitoring and evaluation, should also be social a proper investigation, monitoring and evaluation mechanism makes the diversification of professional characteristics, so as to ensure the professional development characteristics.

\section{Conclusion}

The characteristics of Applied Undergraduate Colleges of professional construction, first need to do market research, grasp the latest market trends, and secondly to strengthen infrastructure construction work, which provides good support for specialty teaching, finally to improve the monitoring and evaluation mechanism, through the development of health evaluation system in accordance with the actual situation of the specialty ensure good, professional development characteristics, discover and solve the problem of professional characteristics encountered in the process of development, and enhance the market competitiveness of specialty construction, cultivate talents meet the social and market demand, to inject new vitality into the development of the country.

\section{References}

[1] An Bo. The construction of characteristic specialty in Applied Undergraduate Universities [J]. Heilongjiang Education (Higher education research and evaluation), 2015,12:44-45.

[2] Chen Fei. The adjustment and reform of Applied Undergraduate Education Curriculum [D]. East China Normal University, 2014

[3] Niu Shengqin, Liu Donghui, Ji toll. The construction of teaching faculty in newly applied undergraduate colleges practice teaching on foreign soft [A]. Beijing Institute of information technology. The fifth century innovation education forum [C]. Beijing: foreign soft information technology research institute, 2016:1. 
[4] Sun Dong. Study on Characteristic Specialty Construction of newly built undergraduate college [D]. Nanjing Normal University, 2013

[5] Ge Chunfeng. The exploration of the construction of the specialty group in the newly applied undergraduate colleges [J]. Higher Vocational Education (Journal of Tianjin Vocational Institute), 2013,02:48-51.

[6] Liu Dongxing. Study on the construction of internal teaching quality assurance system in Applied Undergraduate Universities in China [D]. Huaibei Normal University, 2014 